\title{
Pediatrik Populasyonda Foramen Mentale Lokalizasyonunun Üç Boyutlu Bilgisayarlı Tomografi ile Değerlendirilmesi
}

\section{Evaluation of Mental Foramen Localization by Three Dimensional Computed Tomography in Pediatric Population}

\author{
Hatice Bircan Barlak ${ }^{1}$, Ozan Turamanlar ${ }^{2 *}$, Çiğdem Özer Gökaslan ${ }^{3}$, Özlem Eryiğit ${ }^{4}$, \\ Ayşe Tolunay Oflu ${ }^{5}$
}

\author{
${ }^{1}$ Soma Devlet Hastanesi, Manisa, Türkiye \\ ${ }^{2}$ Afyonkarahisar Sağlık Bilimleri Üniversitesi Tıp Fakültesi Anatomi Anabilim Dalı, Afyonkarahisar, Türkiye \\ ${ }^{3}$ Afyonkarahisar Sağlık Bilimleri Üniversitesi Tıp Fakültesi Radyoloji Anabilim Dalı, Afyonkarahisar, Türkiye \\ ${ }^{4}$ Afyonkarahisar Sağlık Bilimleri Üniversitesi Sağlık ve Uygulama Hastanesi, Afyonkarahisar, Türkiye \\ ${ }^{5}$ Afyonkarahisar Sağlık Bilimleri Üniversitesi Tıp Fakültesi Çocuk Sağlığı ve Hastalıkları Anabilim Dalı, \\ Afyonkarahisar, Türkiye \\ e-mail: hatice.barlak@gmail.com, ozanturamanlar@hotmail.com,ozercigdem@gmail.com, \\ fztumiteryigit@hotmail.com, ayseoflu@gmail.com \\ ORCID: 0000-0003-2254-1265 \\ ORCID: 0000-0002-0785-483X \\ ORCID: 0000-0001-5345-1735 \\ ORCID: 0000-0002-8471-6772 \\ ORCID: 0000-0002-5389-2220 \\ *Sorumlu Yazar / Corresponding Author: Ozan Turamanlar ${ }^{2}$ \\ Gönderim Tarihi / Received: 09.04.2020 \\ Kabul Tarihi / Accepted: 01.06.2020 \\ DOI: $10.34087 /$ cbusbed.717383
}

Giriş ve Amaç: Foramen mentale, corpus mandibulae'nın ön yüzünde bulunan anatomik olușumdur. Foramen mentale'nin lokalizasyonu ve tespiti, dental işlemler, endodontik tedaviler, implant uygulamaları, premolar bölgedeki cerrahi işlemler ve lokal anestezinin tam olarak yapılabilmesi açısından önemlidir. Foramen mentale'nin yerinin ırklara, kişiden kişiye ve yaşlanmayla değiştiği belirtilmiştir. Bu çalışmanın amacı, pediatrik populasyonda foramen mentale'nin lokalizasyonunu belirlemek ve yaş, cinsiyet ve yerleşimine (săg/sol) göre canlı kişilerde üç boyutlu bilgisayarlı tomografi kullanarak değerlendirmektir.

Gereç ve Yöntemler: Tanımlayıcı tipteki bu çalışma, retrospektif olarak herhangi bir nedenle kraniyal bilgisayarlı tomografisi çekilmiş yaş ortalaması $9,11( \pm 2,70)$ olan 99 bireyin görüntüleri üzerinde yapılmıştır. Ölçüm yerlerimiz, foramen mentale üst kenarı ile alveoler krest noktası arası dikey mesafe (E1), foramen mentale'nin alt kenarı ile mandibula'nın alt kenarı arasındaki dikey mesafe (E2), foramen mentale'nin medial kenarı ile symphysis menti noktası arası mesafe (E3) ve foramen mentale'nin lateral kenarı ile ramus mandibula'nın arka sınırı arası mesafe (E4) şeklindedir.

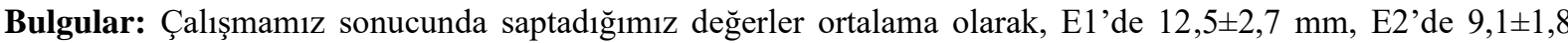

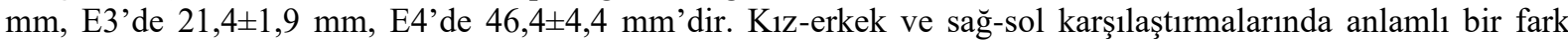
yoktu. Yaş ile E2, E3, E4 ölçümleri arasında pozitif yönde korelasyon bulundu.

Sonuç: Pediatrik populasyonda foramen mentale lokalizasyonun tam olarak bilinmesi premolar bölgede yapılacak olan cerrahi uygulamalarda, anestezi uygulamalarında komplikasyonların azaltılması açısından büyük önem arz etmektedir.

Anahtar kelimeler: Foramen mentale, pediatrik popülasyon, üç boyutlu bilgisayarlı tomografi.

\footnotetext{
Abstract

Objective: Mental foramen is the anatomical formation on the anterior surface of the body of mandible. The localization and detection of mental foramen is important in terms of dental procedures, endodontic treatments, implant applications, surgical procedures in the premolar region and local anesthesia. It is stated that the place of mental foramen changes with races, from person to person and with aging. Our aim is to know the localization of
} 
the mental foramen in the pediatric population and to evaluate it using three-dimensional computed tomography in living people according to age, gender and location (right / left).

Material and Metods: This descriptive study was performed retrospectively on the images of 99 individuals with a mean age of $9.11( \pm 2.7)$ who underwent cranial computerized tomography for any reason. Our measurement locations is the vertical distance between the upper edge of the mental foramen and the point at the alveolar crest (E1), vertical distance between the lower edge of the mental foramen and the lower edge of the mandible (E2), the distance between the medial edge of the mental foramen and the point at the mandibular symphysis (E3) and the distance between the lateral edge of the mental foramen and the point at the back border of the ramus of mandible (E4).

Results: The values we determined as a result of our study were, on average, $12.5 \pm 2.7 \mathrm{~mm}$ in E1, $9.1 \pm 1.8 \mathrm{~mm}$ in E2, $21.4 \pm 1.9 \mathrm{~mm}$ in E3, $46.4 \pm 4.4 \mathrm{~mm}$ in E4.There was no significant difference between girls-boys and left-right comparisons. There was positive correlation between age and E2, E3, E4 measurements.

Conclusion: Precise localization of the mental foramen in the pediatric population is of great importance in reducing the complications of anesthesia in surgical applications to be performed in the premolar region.

Keywords: Mental foramen, pediatric population, three dimensional computerized tomography

\section{Giriş}

Foramen mentale, canalis mandibularis'in corpus mandibulae'sının ön yüzünde bulunan anatomik oluşumdur. $\mathrm{Bu}$ delikten ön-alt dudak bölgesini besleyen damarlar ile birinci molar dişin medialinden orta hatta kadar olan bölgedeki alt dudak, çene ucu, yanak ve diş etinin duyusal inervasyonunu sağlayan sinir çıkmaktadır [1,2]. Foramen mentale'nin yeri, 1 . ve 2. premolar dişler arasındaki hattın altında veya 2 . premolar diş hizasında olarak tanımlanmaktadır. Foramen mentale, oval ya da yuvarlak olabilmektedir. Deliğin açılış doğrultusu ise posterior yönde dışarı ve yukarı doğru olacak şekildedir [3]. Foramen mentale'nin yeri 1rklara, kişiden kişiye farklılık gösterdiği gibi yaşlanmayla da distale kaydığı belirtilmiştir [4]. Dvorak, postnatal gelişim sürecinde foramen mentale'nin yaş ile birlikte yerinin değiştiğini gözlemlemiş ve ilk defa foramen mentale asimetrisinden bahsetmiştir [5].

Çalışmamızın amacı, pediatrik populasyonda foramen mentale'nın lokalizasyonunu bilmek ve yaş, cinsiyet ve yerleşimine [sağ/sol] göre canlı kişilerde üç boyutlu bilgisayarlı tomografi [BT] kullanarak değerlendirmektir. Yaşa bağlı olarak foramen mentale'nin konumunun radyografik olarak değerlendirilmesi daha güvenli bir prosedür için önemlidir. Biz de özellikle pediatrik grupta foramen mentale'nin anatomik yeri ve morfolojisini belirleyerek plastik cerrahi ve diş hekimliği cerrahisinde, dental işlemlerde ağız ve çene cerrahlarına ve anestezistlere önemli katkı sağlayacağ 1 ve ortaya çıkabilecek komplikasyonları en aza indirebilme inancındayız.

\section{Materyal ve Metot}

Çalışma için Dumlupınar Üniversitesi Girişimsel Olmayan Klinik Araştırmalar Etik Kurulunun 18.01.2016 tarih 2016/17 sayılı kararı ile etik çalışma onayı alındı. Çalışmamız Afyonkarahisar Sağlık Bilimleri Üniversitesi Tıp Fakültesi Anatomi ve Radyoloji Anabilim Dalı'nda gerçekleştirildi. Bu araştırma, 99 çocuk bireyin daha önceden herhangi bir sebeple çekilen BT' leri üzerinden yapıldı. 6-14 yaş arası, k1z ya da erkek bireylere ait daha önceden çekilen kranial BT'lerden foramen mentale'nin mandibula üzerindeki belirlenen yerlere olan uzaklıkları ölçüldü. 6 yaşından küçük, 14 yaşından büyük olanlar, ölçümü etkileyebilecek mandibular patolojisi ve/veya malformasyonu olanlar, çekim kalitesi kötü olan bireylerin BT görüntüleri çalışmaya dahil edilmedi.

Ölçüm sağ ve sol olmak üzere her iki foramen mentale'de yapıldı. Ölçüm noktalarına ait bilgi Tablo 1 'de ifade edildi.

Tablo 1. Ölçüm noktalarının adı ve tanımı

\begin{tabular}{|c|l|}
\hline $\begin{array}{c}\text { Ölçümün } \\
\text { Adı }\end{array}$ & \multicolumn{1}{c|}{ Ölçüm Noktasının Tanımı } \\
\hline E1 & Foramen mentale'nin üst kenarı ile alveoler krest noktası arasındaki dikey mesafe \\
\hline E2 & Foramen mentale'nin alt kenarı ile mandibula'nın alt kenarı arasındaki dikey mesafe \\
\hline E3 & Foramen mentale'nin medial kenarı ile symphysis menti noktası arası mesafe \\
\hline E4 & Foramen mentale'nin lateral kenarı ile ramus mandibulae'nın arka sınırı arası mesafe \\
\hline
\end{tabular}



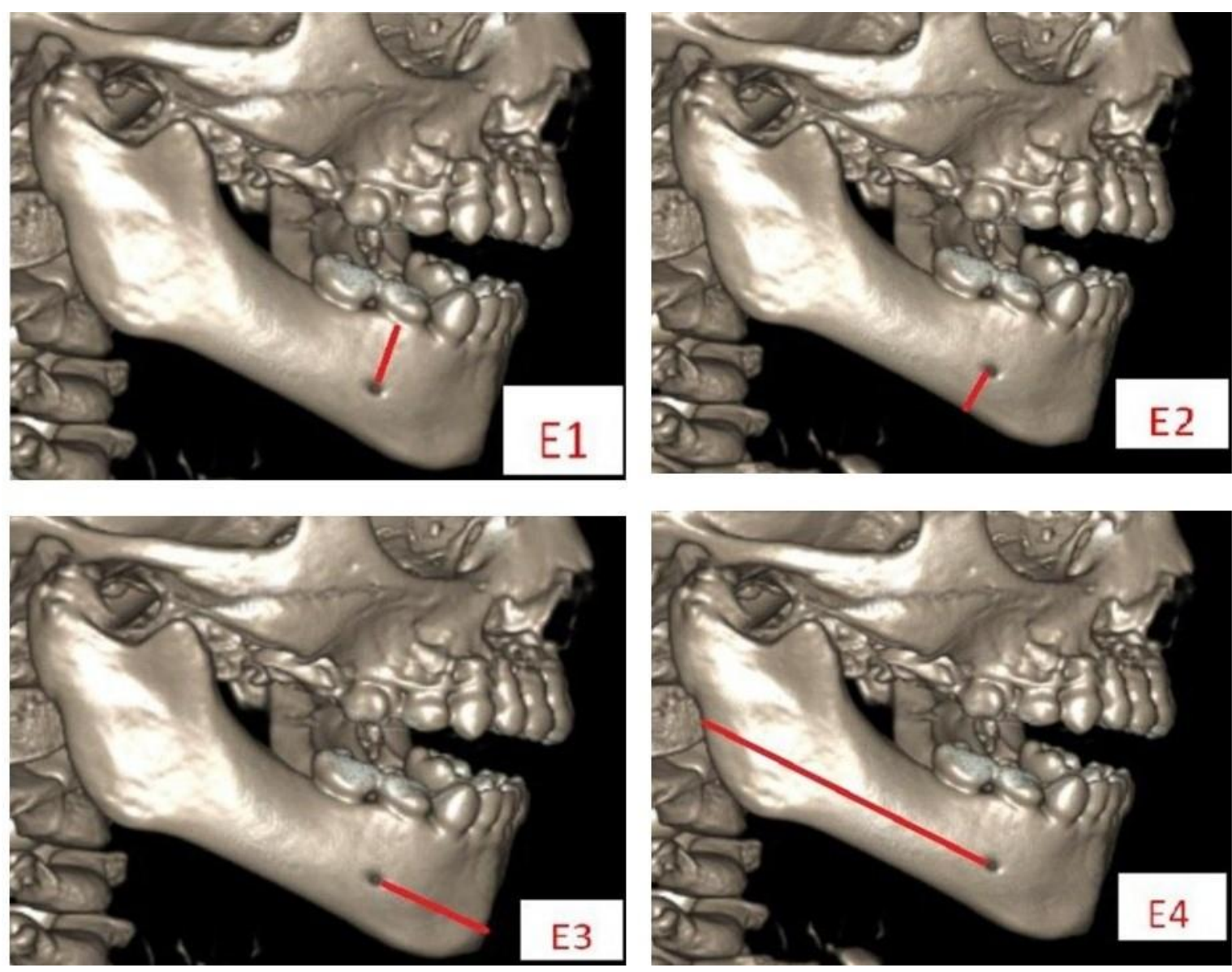

Resim 1. E1, E2, E3 ve E4 Ölçüm Yerleri

\subsection{Istatistiksel Analiz}

İstatistiksel analiz için SPSS 18.0 paket programı kullanıldı. Tanımlayıcı analizler ortalama, ortanca, standart sapma ve yüzde dağılımlar olarak değerlendirildi. Değişkenlerin normal dağılıma uygunluğu görsel (histogram ve olasılık grafikleri) ve analitik yöntemlerle (Kolmogorov-Smirnov ve Shapiro-Wilk testleri) incelendi. Sürekli değişkenlerin karşıllaştırılmasında parametrik koşulların sağlandığı durumlarda Bağımsız Grup T Testi, normal dağılıma uymayan (parametrik olmayan) veri setlerinde Mann-Whitney U Testi kullanıldı. İki sürekli verinin korelasyonunu değerlendirirken Pearson Testi kullanıldı. Bütün testlerde istatistiksel önem düzeyi $\mathrm{p}<0,05$ olarak anlamlı kabul edildi.

\section{Bulgular ve Tartışma}

Çalışmamıza, yaşları 6 ile 14 arasında değişen, yaş ortalaması $9,11( \pm 2,70)$ olan 99 kişi dahil edildi. Kişilerin $36(\% 36,4)$ 'sı kız, $63(\% 63,6)$ 'ü ise erkekti (Grafik 1).

Tüm bireylerde yapılan milimetre cinsinden $(\mathrm{mm})$ ölçümlerin minimum $(\min )$ ve maksimum (max) değerleri ile ortalama (ort) ve standart sapmaları (ss)

hesaplandı (Tablo 2). Sağ ve sol taraftan yapılan E1, E2, E3 ve E4 mesafe ölçümlerinin ortalamalarının karşılaştırılması yapıldı. Mesafe ölçümleri arasında sağ ve sol taraf arasında istatistiksel anlamlı fark saptanmadi (Tablo 3). Sağ ve sol taraftan yapılan E1, E2, E3 ve E4 mesafe ölçümlerinin cinsiyete göre karşılaştırılması yapıldı ve gruplar arasında anlamlı fark saptanmadı (Tablo 4). Bu sonuca göre foramen mentale'nin yaş faktörü ve sağ-sol taraftan etkilenmediği tespit edildi. Yaş ile E1, E2, E3 ve E4 mesafe ölçümleri arasındaki ilişki değerlendirildiğinde, E2, E3 ve E4 mesafe ölçümlerinin yaş ile pozitif yönde anlamlı korelasyon gösterdiği saptandı (Tablo 5). Foramen mentale'nin lokalizasyonu ve tespiti, dental işlemler, endodontik tedaviler, implant uygulamaları, premolar bölgedeki cerrahi işlemler ve lokal anestezinin tam olarak yapılabilmesi açısından önemlidir [2].

Cerrahi işlemler sırasında canalis mandibularis veya foramen mentale bölgesine yapılacak yanlış uygulamalar nervus mandibularis, nervus mentalis ve beraberindeki damar yapıların hasarıla sonuçlanabilir. Buna bağlı olarak duyu kaybı ve hematom oluşabilir $[6,7]$. 


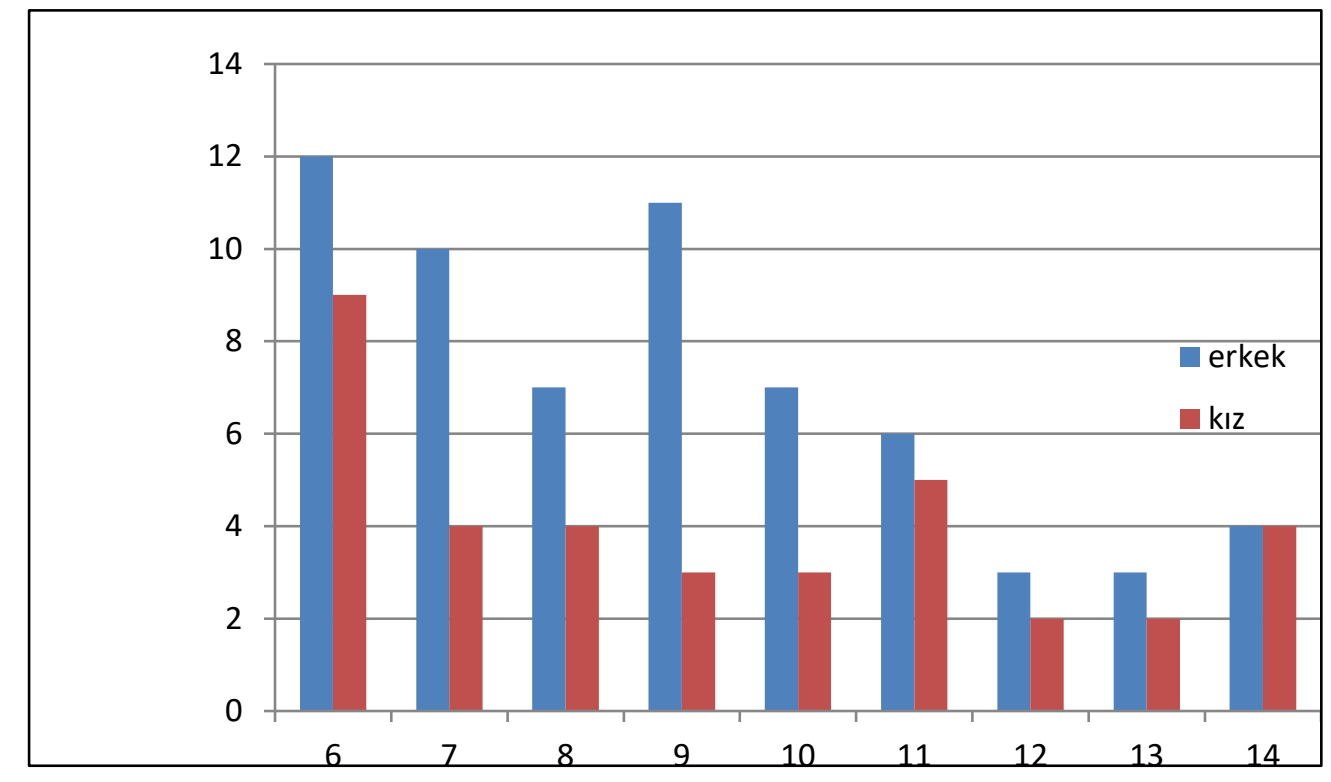

Grafik 1: Yaşlarına göre bireylerin dağılımı

Tablo 2: Tüm bireylerde yapılan ölçümlerin ortalama ve standart sapmaları

\begin{tabular}{|c|c|c|c|}
\hline \multicolumn{2}{|c|}{} & $\begin{array}{c}\text { Min-max } \\
(\mathrm{mm})\end{array}$ & $\begin{array}{c}\text { ort } \pm \text { ss } \\
(\mathrm{mm})\end{array}$ \\
\hline \multirow{2}{*}{ E1 } & Sağ & $6.5-16.1$ & $12.5 \pm 2.7$ \\
\cline { 2 - 4 } & Sol & $8.1-19.3$ & $12.5 \pm 1.7$ \\
\hline \multirow{2}{*}{ E2 } & Sağ & $5.08-15.2$ & $9.1 \pm 1.8$ \\
\cline { 2 - 4 } & Sol & $5.4-14.5$ & $9.1 \pm 1.9$ \\
\hline \multirow{3}{*}{ E3 } & Sağ & $15.6-26.4$ & $21.4 \pm 1.9$ \\
\cline { 2 - 4 } & Sol & $18.4-26.4$ & $21.7 \pm 1.6$ \\
\hline \multirow{2}{*}{ E4 } & Sağ & $35.7-61.6$ & $46.4 \pm 4.4$ \\
\cline { 2 - 4 } & Sol & $35-58.3$ & $45.9 \pm 4.2$ \\
\hline
\end{tabular}

Tablo 3: Sağ ve sol taraftan yapılan E1, E2, E3 ve E4 mesafe ölçümlerinin karşılaş̧ırıılması $(p>0,05)$.

\begin{tabular}{|c|c|c|c|}
\hline & & ortalama & $\mathrm{p}$ \\
\hline \multirow{2}{*}{ E1 } & Sağ & 101.44 & \multirow{2}{*}{.634} \\
\hline & Sol & 97.56 & \\
\hline \multirow{3}{*}{ E2 } & Sağ & 99.24 & \multirow{3}{*}{.949} \\
\hline & & & \\
\hline & Sol & 99.76 & \\
\hline \multirow{2}{*}{ E3 } & Sağ & 95.35 & \multirow{2}{*}{.308} \\
\hline & Sol & 103.65 & \\
\hline \multirow{3}{*}{ E4 } & Sağ & 102.33 & \multirow{3}{*}{.487} \\
\hline & & 0667 & \\
\hline & Sol & 96.67 & \\
\hline
\end{tabular}


Tablo 4. Sağ ve sol taraftan yapılan E1, E2, E3 ve E4 mesafe ölçümlerinin cinsiyete göre karşılaştırması(p>0,05)

\begin{tabular}{|c|c|c|c|c|c|c|}
\hline & & \multicolumn{2}{|c|}{$\mathrm{K} 1 \mathrm{z}(\mathrm{n}: 36)$} & \multicolumn{2}{|c|}{ Erkek (n:63) } & \multirow[b]{2}{*}{$\mathrm{p}$} \\
\hline & & $\begin{array}{c}\text { Min-max } \\
(\mathrm{mm})\end{array}$ & ort \pm Ss $(\mathrm{mm})$ & $\begin{array}{c}\text { Min-max } \\
(\mathrm{mm})\end{array}$ & ort \pm ss $(\mathrm{mm})$ & \\
\hline \multirow[t]{2}{*}{ E1 } & Sağ & $6.5-16.1$ & $12.5 \pm 2.3$ & $8.0-15.6$ & $12.5 \pm 1.5$ & .881 \\
\hline & Sol & $8.1-16.4$ & $12.6 \pm 1.6$ & $8.1-19.3$ & $12.6 \pm 1.8$ & .947 \\
\hline \multirow[t]{2}{*}{$\mathrm{E} 2$} & Sağ & $6.7-14.0$ & $9.1 \pm 1.7$ & $5.1-15.2$ & $9.1 \pm 2.0$ & .956 \\
\hline & Sol & $6.6-14.5$ & $9.8 \pm 2.0$ & $5.4-14.5$ & $9.4 \pm 2.0$ & .558 \\
\hline \multirow[t]{2}{*}{ E3 } & Săg & E1 & $21.0 \pm 2.0$ & $17.6-26.4$ & $21.7 \pm 1.9$ & .109 \\
\hline & Sol & $18.4-26.4$ & $21.5 \pm 1.8$ & $18.4-26.4$ & $21.7 \pm 1.8$ & .570 \\
\hline \multirow[t]{2}{*}{ E4 } & $\overline{\mathrm{Sag}}$ & $35.7-56.1$ & $46.6 \pm 4.3$ & $36.7-61.6$ & $46.4 \pm 4.6$ & .749 \\
\hline & Sol & $35.0-58.3$ & $46.1 \pm 4.8$ & $35.0-58.3$ & $46.2 \pm 4.4$ & .703 \\
\hline
\end{tabular}

Tablo 5. Yaş ile E1, E2, E3 ve E4 mesafe ölçümlerinin korelasyonu (r: Pearson korelasyon katsayısı).

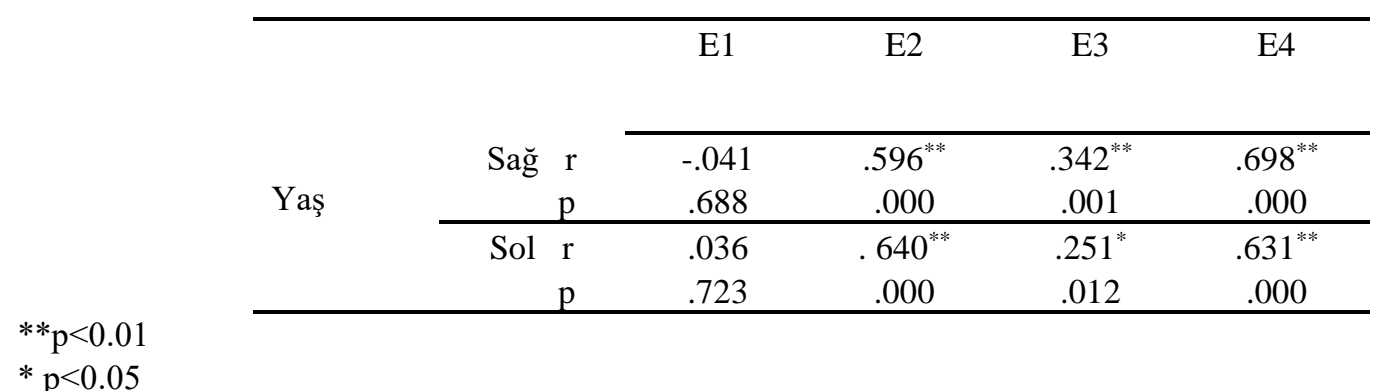

Foramen mentale'nin varlığ 1 kuru kafatasında mikroskopik olarak incelenebilir. Panoromik görüntüler ve BT görüntüleri de dahil olmak üzere farklı yöntemlerle de değerlendirilebilir. Panoromik radyografilerde basit prosedür, düşük radyasyon dozu, daha hızlı görüntü elde etme avantaj iken düşük tanılama derecesi ve detayları, çarpıklıkların varlığı ve anatomik yapıların örtüşmesi dezavantajlarıdır. Çalışmamızda BT kullanmamızın nedeni, BT'nin seçilen bölgenin anatomisinin kapsamlı bir şekilde üç boyutlu görüntüler üretmek suretiyle anatomik varyasyonların tanımlanmasına ve değerlendirilmesine izin veren yararlı bir araç olmasindan dolayıdır. [8-12] Foramen mentale ile ilgili yapılan araştırmalardaki olgular genellikle erişkin kişilerdir. $\mathrm{Bu}$ durum, çalışmamızın spesifikliğini arttırmasına rağmen karşılaştırma yapma durumunu azaltmaktadır. Mohamed ve ark., Hint popülasyonunda dijital panaromik radyografiler ile 6-12 yaş grubunda E1 değerini k1zlarda 14,48 mm, erkeklerde 14,36 mm; 13-18 yaş grubunda E1 değerini kızlarda 15,58 mm erkeklerde 16,16 mm olarak bulmuşlardır [13]. Bu sonuçlara göre yaş grubu dikkate alındığında Mohamed ve ark.'nın bu yaş gruplarında bulduğu değerler ile çalışmamızdaki sonuçlar arasında benzerlik bulunmaktadır. Haktanır ve ark. E1 değerinin sağ ve sol ölçümleri arasında istatistiksel olarak anlamlı bir fark bulamamışlardır [8]. Benzer şekilde çalışmamızda da sağ ve sol ölçümleri arasında anlamlı bir fark saptayamadık.

E2 değerini panoramik radyografiler ile saptayan çalışmalardan Mohamed ve ark., Hint populasyonunda ve 6-12 yaş grubunda kızlarda 
9,70 mm ve erkeklerde $8,58 \mathrm{~mm}$ bulmuşlardır. 1318 yaş grubunda ise kızlarda $12,70 \mathrm{~mm}$, erkeklerde 13,12 mm olarak bulmuşlardır [13]. Bizim çalışmamızda bu değer ortalama 9,1 mm'dir. E1'de olduğu gibi E2'de de bulduğumuz değerin Mohamed ve arkadaşlarının sonuçlarına yakınlık gösterdiğini gözlemledik. Sheikhi ve ark. sağda ve solda anlamlı bir fark olmadığını ifade etmişlerdir [14]. Çalışmamızda da sağ ve sol karşılaştırmasında ölçümler arasında anlamlı bir fark bulunamadı.

Çalışmamızda, E3 değerini ortalama olarak 21,5 mm saptadık. Literatür araştırmalarımızda E3 değerini pediatrik populasyonda değerlendiren herhangi bir çalışmaya rastlayamadık. Dolayısıyla literatürdeki değerlerin bizim ölçümlerimize göre daha büyük olmasının nedeni, bu çalışmaların erişkinler üzerinde yapılmasından kaynaklanmaktadır. Literatürde E3 değerini sağ-sol olarak karşılaştıran çalışmalarda Haktanır ve ark. ve Sheikhi ve ark. istatistiksel olarak anlamlı bir fark bulamamışlardır [8,14]. Bizim çalışmamızda da E3 değerinin sağ ve sol karşılaştırmasında da anlamlı bir fark bulunmad.

Çalışmamızda E4 değerini ortalama 46,1 mm olarak saptadık. E4 sağ-sol ölçümler arasında anlamlı bir fark bulunamadı. Literatürde ise böyle bir karşılaştırma yapılmamıştır.

Gungor ve ark. Türk populasyonunda 107 erkek, 103 kız ve kadın bireylerde bilgisayarlı tomografi cihazını kullanarak yaptıkları ölçümlerde foramen mentale'nin cinsiyete göre karşılaştırmasında kadınlarda bulunan değerlerin erkeklere göre anlamlı olacak şekilde daha düşük bulmuşlar [15]. Bizim çalışmamızda kız ve erkek karşılaştırmasında anlamlı bir fark yoktur. Mohamed ve ark. 6-12 yaş grubunda E1 değerini kılarda $14,48 \mathrm{~mm}$ ve erkeklerde 14,36 mm; E2 değerini kılarda 9,70 $\mathrm{mm}$ ve erkeklerde $8,58 \mathrm{~mm}$ olarak bulmuşlardır. E2 değerinde kızlarda erkeklere oran ile anlamlı bir artış gözlemlemişlerdir [13]. K1z ve erkekler arasındaki foramen mentale'deki pozisyon değişikliğini pubertel büyüme ile ilişkilendirmişlerdir.

Dotto ve ark. 10 ile 12 yaş arasındaki bireylerde panaromik grafiler ile yaptıkları çalışmada sadece sol taraflı ölçüm yapmışlar ve E2 ile yaş karşılaştırıldığında anlamlı bir fark bulmuşlardır. Aynı çalışmada E1 ile yaş arasında anlamlı bir fark bulunmadığını gözlemlemişlerdir [16]. Bu çalışma ile yaşın artması ile foramen mentale'nin pozisyonunda bazı değişiklikler olabileceği sonucuna varmışlardır. Sheikhi ve ark. E2 değeri ile yaş arasında ilişki saptarken, E3 ölçümü ile yaş arasında ilişki olmadığı sonucuna varmışlardır [14]. Jo ve ark. 6-13 yaş arasındaki çocukların panoromik görüntülerinden yaptıkları ölçümlerde, yaş arttıkça foramen mentale'nin arkaya ve aşağ 1 doğru hareket ettiği sonucuna varmışlardır [17]. Bizim çalışmamızda tüm ölçümlerin yaşa bağlı korelasyonuna bakıldığında, yaş ile E2, E3, E4 ölçümleri arasında pozitif yönde korelasyon bulundu. Yaş ile E1 arasında ise anlamlı bir korelasyon yoktu.

Foramen mentale'nin lokalizasyonunu, sınırlarını ve boyutunu bilmek, dental işlemler, endotontik tedaviler, implant uygulamaları ve bu bölgedeki cerrahi işlemler ile lokal anestezinin tam olarak yapılabilmesi açısından önemlidir. Foramen mentale'nin klinik önemi olmasına rağmen lokalizasyonu açısından anatomik varyasyonlarından dolayı tam bir görüş birliği yoktur [15, 18]. Çünkü yaşın artması ile birlikte mandibula'nın gelişimine paralel olarak foramen mentale'nin lokalizasyonu da değişebilmektedir [19].

\section{Sonuç}

Pediatrik populasyonda foramen mentale lokalizasyonun tam olarak bilinmesi premolar bölgede yapılacak olan cerrahi uygulamalarda, anestezi uygulamalarında komplikasyonların azaltılması açısından büyük önem arz etmektedir. Çalışmamızda pediatrik populasyondaki bireylere ait bilgisayarlı tomografi görüntüleri üzerinden foramen mentale lokalizasyonunu belirleyerek yaş, cinsiyet ve yerleşimine göre değişimlerini tanımlayarak klinik değerlendirmelere katk1 sağlamayı amaçladık.

\section{Teşekkürler}

Çalışmamıza desteklerinden dolayı Prof. Dr. İsmet Doğan ve Dr. Hasan Nadir Rana'ya teşekkür ederiz. $\mathrm{Bu}$ çalışma, Afyon Kocatepe Üniversitesi Sağlık Bilimleri Enstitüsü'nde ve danışmanlığını Doç. Dr. Ozan Turamanlar'ın yaptığı, Hatice Bircan Barlak'ın yükssek lisans tezinden üretilmiştir.

Bu çalıșma, 06-09 Eylül 2018 tarihleri arasında Konya'da yapılan 1. Uluslararası Akdeniz Anatomi Kongresi (IMAC 2018)'nde poster bildirisi olarak sunulmuştur.

\section{References}

1. Büyükakyüz, N, Kuru, Eİ, Foramen mentalenin lokalizasyonu, Istanbul Dis Hekimleri Odast, 2013, 148, 32-5.

2. Ezirganlı, Ş, Özer, K, Sarı, F, Kırmalı, Ö, Kara, Mİ, Mental foramenin lokalizasyonun radyografik olarak değerlendirilmesi, Cumhuriyet Dental Journal, 2010, 13(2), 96-100

3. Koyun, N, Foramen mentale asimetrisi, Van Tip Dergisi, 2007; 14 (3), 80-82.

4. Santini, A, Land, MA, A comparison of the position of the mental foramen in Chinese and British mandibles, Acta Anatomica, 1990, 137, 208-212.

5. Dvorak, J, Asymmetry of vertical localization of the foramen mentale in postnatal development according to age, Ceskoslovenska Stomatologie, 1972, 72, 215-218.

6. Greenstein, G, Tarnow, D, The mental foramen and nerve: Clinical and anatomical factors related to dental implant placement, A literature review, Journal of Periodontology, 2006, 77, 1933-1943.

7. Sharawy, M, Misch, CE, Anatomy for dental implants. In: Misch CE, ed. Contemporary Implant Dentistry, 2nd ed. St. Louis, The CV Mosby Company 1999. 
8. Haktanır, A, Ilgaz, K, Turhan-Haktanır, N, Evaluation of mental foramina in adult living crania with MDCT, Surgical and Radiologic Anatomy, 2010, 32, 351-356.

9. Paraskevas, G, Mavrodi, A, Natsis, K, Accessory mental foramen: An anatomical study on dry mandibles and review of the literatüre, Journal of Oral \& Maxillofacial Surgery, 2015, 19, $177-181$.

10. Khojastepour, L, Location of mental foramen in a selected iranian population: a CBCT assessment, Iranian Endodontic Journal, 2015, 10(2), 117-21.

11. Imada, TSN, Fernandes, LMPdS, Centurion, BS, Oliveira-Santos, C, Honório, HM, Rubira-Bullen, IRF, Accessory mental foramina: prevalence, position and diameter assessed by conebeam computed tomography and digital panoramic radiographs, Clinical Oral Implants Research, 2014, 25(2), e94-e9.

12. Naitoh, M, Hiraiwa, Y, Aimiya, H, Gotoh, K, Ariji, E, Accessory mental foramen assessment using cone-beam computed tomography, Oral Surgery, Oral Medicine, Oral Pathology, Oral Radiology, and Endodontology, 2009, 107(2), 289-94, Epub 2008 Dec 13.

13. Mohamed, A, Nataraj, K, Mathew, VB, Varma, B, Mohamed, S, Valappila, NJ, Meena, AS, Location of Mental Foramen using digital panoramic radiography, Journal of Forensic Dental Sciences, 2016, 8(2), 79-82.

14. Sheikhi, M, Kheir, MK, CBCT assessment of mental foramen position relative to anatomical landmarks, International Journal of Dentistry, 2016, 5821048.

15. Gungor, E, Aglarci, OS, Unal, M, Dogan, MS, Guven, S. Evaluation of Mental Foramen location in the 10-70 years age range using conebeam computed tomography, Nigerian Journal of Clinical Practice, 2017, 20(1), 88-92.

16. Dotto, SR, Travassos, RM, Filho, EM de Moraes, LC, de Moraes ME, Castilho, JC, Porto, COTW, Dotto, PP, Evaluation of the mental foramen position in pediatric patients, Ciência Odontológica Brasileira, 2006, 9, 14-20.

17. Jo, E, Lee, J, Ra, J, A Study on Position of the Mental Foramen in Children Using Panorama, Journal of the Korean Academy of Pediatric Dentistry, 2019, 46(2).

18. Kaffe, I, Ardekian, L, Gelerenter, I, Yaicher, S, Location of the mandibular foramen in panoramic radiographs, Oral Surgery, Oral Medicine, Oral Pathology, and Oral Radiology, 1994, 78, $662-665$.

19. Gupta, T, Localization of important facial foramina encountered in maxillo-facial surgery, Clinical Anatomy, 2008, 21, 633-640.

http://edergi.cbu.edu.tr/ojs/index.php/cbusbed isimli yazarın CBU-SBED başlıklı eseri bu Creative Commons Alıntı-Gayriticari4.0 Uluslararası Lisans1 ile lisanslanmıştır.

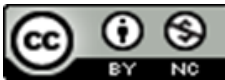

